\title{
Clinical Analysis of External Auditory Canal Osteoma
}

\author{
Young Soo Kim, Min Hyuck Kang, Young-Seok Choi, See-Ok Shin ${ }^{\mathbb{D}}$, and Hahn Jin Jung ${ }^{(D)}$ \\ Department of Otolaryngology-Head and Neck Surgery, Chungbuk National University Hospital, \\ Chungbuk National University College of Medicine, Cheongju, Korea
}

\section{외이도 골종의 임상 양상}

김영수 · 강민혁 · 최영석 · 신시옥 · 정한진

충북대학교 의과대학 충북대학교병원 이비인후과학교실

\author{
Received November 12, 2018 \\ Revised January 11, 2019 \\ Accepted January 21, 2019 \\ Address for correspondence \\ Hahn Jin Jung, MD \\ Department of Otorhinolaryngology- \\ Head and Neck Surgery, \\ Chungbuk National University \\ Hospital, Chungbuk National \\ University College of Medicine, \\ 776 1sunhwan-ro, Soewon-gu, \\ Cheongju 28644, Korea \\ Tel +82-43-269-6157 \\ Fax +82-43-265-6157 \\ E-mail hahnjin2@naver.com \\ See-Ok Shin, MD, PhD \\ Department of Otorhinolaryngology- \\ Head and Neck Surgery, \\ Chungbuk National University \\ Hospital, Chungbuk National \\ University College of Medicine, \\ 776 1sunhwan-ro, Soewon-gu, \\ Cheongju 28644, Korea \\ Tel +82-43-269-6157 \\ Fax +82-43-265-6157 \\ E-mail soshin@chungbuk.ac.kr
}

\begin{abstract}
Background and Objectives External auditory canal osteoma is ancommon benign lesion and represents as unilateral solitary pedunculated mass. The aim of this study is to evaluate the clinical symptoms of osteoma and its treatment outcomes over a 10 -year period in a tertiary hospital.
\end{abstract}

Subjects and Method Eight patients underwent operation to remove an external auditory canal osteoma at Chungbuk National University Hospital from 2008 to 2017. The medical records were retrospectively reviewed with regard to clinical characteristics, size and location of osteoma, method of surgery and treatment outcomes.

Results The average age of patients was 41.8 years with the male predominance of $6: 2$. All of the lesions in the osteoma were unilateral and solitary (average size $5.0 \mathrm{~mm}$ ). All of the eight cases were pedunculated: in four cases, the stalks of the osteoma were found on the tympanomastoid suture line and in three cases, it was found on the tympanosquamous suture line. Four patients were asymptomatic, where the lesions were found incidentally during unrelated evaluations. No patients were found with conductive hearing loss in the pure tone audiometry. Transcanal and endaural approach were used in five and three cases, respectively. Most of the cases were removed by curettage only, except for the two who needed additional drilling. The average surgery time was 15.6 minutes. There was no postoperative complication or recurrence. Conclusion The external auditory canal osteoma was mostly unilateral and solitary. The removal of osteoma in the early stage was relatively easy with no recurrence or complication. Korean J Otorhinolaryngol-Head Neck Surg 2019;62(6):332-5

Key Words Exostosis · External auditory canal · Osteoma.

\section{서 론}

외이도 골종은 발생 빈도가 매우 낮은 질환이며, 외이도 골종 제거를 위한 수술은 전체 귀 수술의 약 $0.05 \%$ 를 차지 한다. ${ }^{1)}$ 외이도 골종은 주로 외이도의 협부 외측에 발생한다 고 알려져 있으며, 피부 밑에 반구형 모양으로 발생하여 외이 도의 폐쇄를 초래할 수 있는 양성 골종양이다. ${ }^{2,3)}$ 정확한 발생

This is an Open Access article distributed under the terms of the Creative Commons Attribution Non-Commercial License (https://creativecommons.org/licenses/by-nc/4.0) which permits unrestricted non-commercial use, distribution, and reproduction in any medium, provided the original work is properly cited.
원인은 밝혀지지 않았고 초기에는 대부분 무증상이나, 전음 성 난청, 이내 충만감, 이통, 소양감 등을 일으킬 수 있다.,5) 증상이 없을 경우 보존적 치료를 할 수 있으나 크기가 커져 서 증상을 일으키면 수술적 제거가 필요하다. 저자들은 최근 10 년간 본원에서 외이도 골종으로 진단되어 수술적 제거술 을 시행한 8예의 임상 양상에 대해 기존의 문헌 고찰과 함께 보고하고자 한다. 


\section{대상 및 방법}

2008년 1월부터 2017년 12월까지, 충북대학교병원 이비인 후과에 내원하여 외이도 골종으로 진단받고 수술을 시행한 8 명의 환자에 대해 의무기록 및 영상 자료를 통해 후향적으 로 연구하였다. 연령 및 성별, 내원 시 증상, 청력검사 결과, 외 이도 골종의 크기, 부착부 및 양상 등에 대해 조사하였고, 수 술을 시행한 환자에서 수술 방법 및 수술 시간, 수술 후 합병 증, 재발 여부 등에 대해 조사하였다. 본 연구는 본원의 임상 시험윤리위원회(Institutional Review Board, IRB No. 201812-003) 심의를 승인 받았다.

수술은 국소마취를 기본으로 하였으나, 환자의 선호도에 따라 전신마취로도 시행하였다. 경외이도(transcanal) 접근 법을 기본으로 하였으며, 외이도 골종의 크기와 위치 등을 고려하여 외이도의 굴곡 등으로 접근 각도가 좋지 않거나 시 야가 안 좋은 경우에는 이내(endaural) 접근법을 사용하였 다. 골종을 덮고있는 피부를 최대한 보존하며 피판을 들어올 린 뒤, 큐렛을 통해 제거하였으며, 골종의 부착부가 일부 남 아있는 경우나 제거된 표면이 거친 경우에 필요에 따라 추가 로 드릴링을 시행하였다. 수술 후 외이도에 간단한 거즈 드레 싱으로 대어 마무리하였고 피부이식을 시행한 경우는 없었 다. 환자는 당일 퇴원 후, 수술 7일째 외래 내원하여 드레싱 을 시행하였다. 환자는 수술 후 최종 6개월까지 합병증 및 재 발여부에 대해 외래에서 경과 관찰 하였다.

\section{결 과}

총 8 명의 환자 중 남자가 6 명, 여자가 2 명이었으며, 평균 나 이는 41.8세였다(Table 1). 8예 모두 일측 단발성(우측 6예, 좌측 2예)의 병변으로 외이도 협부의 외측에서 발견되었다. 환자 내원 시 주증상은 다른 증상으로 검진 중 우연히 발견 된 경우로 외이도 골종으로 인한 특이 증상이 없는 경우가 4 예로 가장 많았으며, 그 밖에 이통, 이충만감 등이 있었다. 외
이도 골종의 크기는 평균 $5.0 \mathrm{~mm}$ 이었으며, 모두 유경성(pedunculated)이었다. 병변 위치는 후하벽 고실유양돌기 봉합 선(tympanomastoid suture) 부위가 4예, 전상벽 고실인상 봉 합선(tympanosquamous suture) 부위가 3예, 그 외 부위가 1예 였다. 수술 전 순음 청력 검사 상 전음성 난청을 보이는 환자 는 없었다. 전산화단층촬영 검사 결과 외이도 골종 소견이 관찰되었으며, 중이내에 염증 등을 보이는 경우는 없었다. 수 술적 제거는 국소마취 하에 4예 시행하였으며, 경외이도 접 근법 5예, 이내 접근법으로 3예 시행하였다. 큐렛으로 8예 제 거하였으며, 2 예의 경우에는 추가로 드릴링을 시행하였다. 수 술시간은 평균 15.6분이었다. 제거된 조직은 Hematoxylineosin 염색에서 중층 편평상피로 완전히 덮여 있고 치밀하고, 성숙된 순수한 지주골로 이루어진 소견을 보여 골종으로 최 종 진단 되었다(Fig. 1). 전례에서 수술 중 고막 천공이나 수 술 후 외이도 협착 등의 합병증은 발생하지 않았다. 수술 후 6 개월까지 추적관찰 시행하였으며, 재발 소견을 보인 경우는 없었다. 2예의 경우 타 질환으로 외래 내원하여 검진을 시행하 였으며, 수술 후 2년 및 3년째 수술로 인한 합병증이나 재발 소견은 보이지 않닸다.

\section{고 찰}

외이도 골종은 드물게 발견되는 양성 골성 종양으로, $3: 1$ 로 남자에서 호발하고, 어느 연령에서나 발생할 수 있으며 매 우 어린 나이에서도 보고되고 있다. ${ }^{1,3}$ 수년간에 걸쳐 서서히 커지기 때문에 대부분 무증상이나, 외이도가 귀지와 파기물 에 의해 폐색되면서 증상이 나타나게 된다. ${ }^{6.7)}$ 가장 흔한 증 상은 전음성 난청과 이내 충만감이며 악취성 이루, 이통, 어 지러움증 및 소양감이 생길 수 있고 ${ }^{7}$ 외이도의 전방부에 생긴 경우 이개측두신경의 압박에 의해 동측의 측두부 두통을 초 래할 수도 있다. ${ }^{45)}$ 본 연구에서도 난청, 이명 등의 증상으로 시행한 검진상 우연히 발견된 무증상의 환자가 4예로 가장 많았고, 이충만감과 이통이 각각 2예였다. 순음청력검사 결

Table 1. Summary of clinical and radiologic findings in patients with osteoma of external auditory canal

\begin{tabular}{|c|c|c|c|c|c|c|c|c|c|}
\hline No. & Sex & Age & Symptom & Site & Size $(\mathrm{mm})$ & Shape & Anesthesia & Approach & Op. time (min) \\
\hline 1 & $\mathrm{~F}$ & 36 & Otalgia & Right & 5 & Pedunculated & General & Endaural & 20 \\
\hline 2 & $M$ & 33 & None & Left & 5 & Pedunculated & Local & Endaural & 15 \\
\hline 3 & $M$ & 24 & Earfullness & Right & 5 & Pedunculated & General & Transcanal & 10 \\
\hline 4 & $M$ & 26 & Otalgia & Right & 5 & Pedunculated & Local & Transcanal & 5 \\
\hline 5 & $M$ & 45 & Earfullness & Right & 6 & Pedunculated & General & Transcanal & 10 \\
\hline 6 & $M$ & 70 & None & Right & 6 & Pedunculated & Local & Transcanal & 10 \\
\hline 7 & $M$ & 76 & None & Left & 5 & Pedunculated & General & Endaural & 50 \\
\hline 8 & $\mathrm{~F}$ & 24 & None & Right & 3 & Pedunculated & Local & Transcanal & 5 \\
\hline
\end{tabular}

F: female, M: male, Op.: operation 

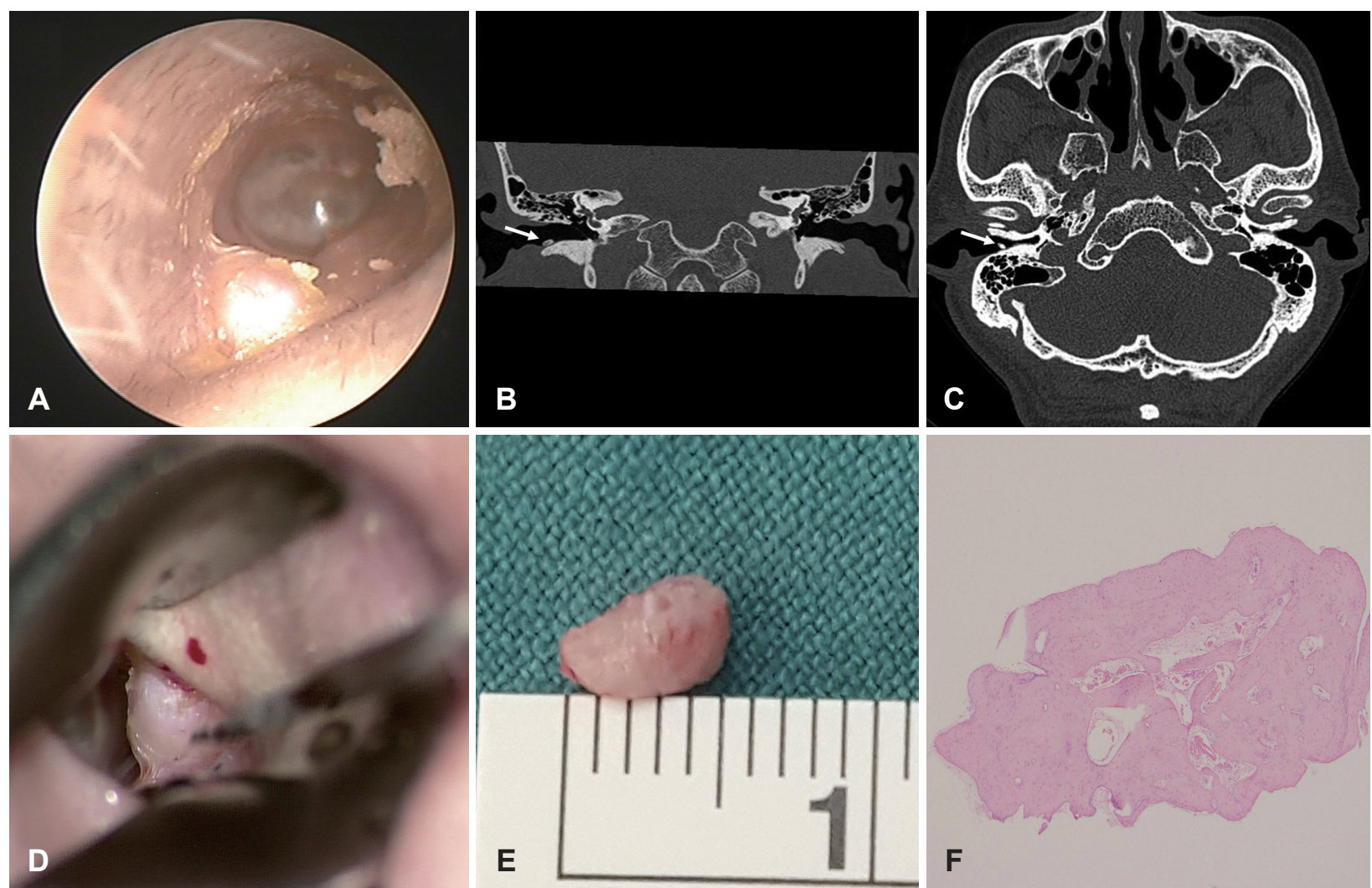

Fig. 1. Pictures of case No. 7. Preoperative finding (A). Coronal (B), and Axial temporal bone computed tomography (C). Intraoperative finding (D). Gross finding (E). Histopathology finding ( $\times 40$ Hematoxylin and Eosin) (F).

과 전음성 난청을 보인 경우는 없었다.

외이도 골종은 골막에서 형성되는 유경성 종괴로 대개 외 이도 협부의 외측에서 발생한다. $\left.{ }^{1,6}\right)$ 촉진 시 단단한 골성 경도 를 보이며 크기는 아주 작은 것부터 외이도를 완전히 폐쇄할 정도로 다양하다.7) 골종은 해면상형(cancellous)과 치밀형 (compact)의 두가지 형태가 있으며, 방사선학적으로 치밀형은 분엽을 보이는 치밀한 골종괴이며 해면상형은 부분적으로 골화를 보이는 골종괴이다. ${ }^{8)}$ 본 연구에서는 특별히 해면상형 또는 치밀형에 대한 구분은 시행하지 않았다. $\mathrm{Graham}^{6}$ 은 외이도 골종이 고실인상 봉합선 또는 고실유양돌기 봉합선 을 따라서 발생한다고 하였고, Sheehy ${ }^{1)}$ 는 일측성, 단발성으 로 대부분 외이도 협부 외측의 고실인상 봉합에 부착한다고 하였다. $\mathrm{Graham}^{6}$ 은 봉합선에는 다른 부위보다 피하조직이 두텁고 혈관이 풍부하기 때문에 골종이 외이도의 봉합선에 서 발생할 것으로 생각하였다. 본 연구에서도 고실유양돌기 봉합선에서 발생한 경우가 4예, 고실인상 봉합선에서 발생한 경우가 3예였다.

병리 조직학적으로 골종은 외이도의 편평상피와 골막으로 덮여 있으며 많은 섬유혈관성 통로들이 층판골(lamellar bone) 에 의해 둘러싸여 있다.,10) 섬유혈관성 통로들은 불규칙하며 많은 섬유 조직과 동모양 혈관(sinusoidal blood vessel)을 포
함하는 경우가 많다. 섬유혈관성 통로 사이의 골모양은 치밀 하고 불규칙하게 여러 방향을 향하며 절단면에서 골세포와 열공은 드물게 관찰된다. ${ }^{6,8)}$

외이도 골종은 크기가 작은 경우 별 증상이 없어 보존적으 로 치료할 수 있다. ${ }^{11)}$ 그러나 크기가 서서히 증가하면서 귀지 나 파기물의 저류로 반복되는 청력 장애와 감염을 유발하므 로 수술적으로 제거하여야 한다. 특히 수술을 조기에 시행할 수록 간단하며, 합병증을 막을 수 있다는 장점이 있다. ${ }^{1)}$ 수술 은 유경성의 종양이 외이도 협부의 외측에 위치하고 크기가 작은 경우에는 국소마취 하에서 경외이도 접근법에 의해 큐 렛이나 드릴을 이용하여 제거가 가능하지만 종양이 외이도 협부의 내측에 위치하면서 협부보다 크거나 부착부위가 넓 은 경우에는 후이개접근법을 통해 제거하는 것이 좋다고 알 려져 있다. ${ }^{12-14)}$ 본 연구에서는 5예의 경우 경외이도 접근법으 로 수술하였고, 3 예에서는 이내 접근법을 사용하였다. 대부 분의 증례에서 큐렛 단독으로 제거하였으나, 2 예의 경우에는 추가로 드릴링을 시행하여 제거하였다. 외이도 골종의 경우 골종의 완전한 절제가 이루어진 경우 재발을 하지 않기 때문 에, 수술 후 예후는 매우 좋다고 알려져 있으며,, 본 연구에서 도 모두 재발없이 경과 관찰 중이다.

외이도 골종의 경우 감별 해야 하는 진단으로 외골증(exos- 
tosis)이 있다. 외골증은 외이도 질환 중 가장 흔한 골성 병변 으로 알려져 있으며 반복적으로 찬물에 노출 시, 또는 감염, 습진, 외상 등에 의해 발생한다. ${ }^{2,3,15)}$ 임상적으로 파도타기꾼 귀(Surfur's ear)라고 불리기도 하는데, 골종과 비교하여 대부 분 양측에 다발성으로 발생하고 외이도 협부 내측의 고실륜 근처에 골종에 비해 무경성의 넓은 기저부를 갖는 경우가 많 다.,6) 병리 조직학적으로 외골증은 풍부한 골세포를 가지고 있는 골막하골의 동심성층을 보이나 섬유혈관 통로는 볼 수 없다는 점이, 풍부한 섬유혈관 통로를 보이는 골종과 다른 점 으로 알려져 있지만, ${ }^{6,11)}$ 외골증과 골종 모두에서 섬유혈관 통 로가 관찰된다는 보고도 있다. ${ }^{16)}$ 외골증은 보존적 치료에 반 응이 없는 경우를 제외하고는 대부분 수술적 치료가 필요하 지 않기 때문에 골종과의 감별이 필수적이다. 그 외에도 다른 연부조직의 병변이나 만성유양돌기염으로 인하여 경화된 경 우와도 감별을 하여야 하며, 드물게 망상골종(cancellous osteoma) 또는 유골골종(osseous osteoma)과도 감별이 필요 할 수 있다.

결론적으로, 외이도 골종은 임상적, 병리학적으로 별개의 질환인 외골증과 감별이 필요한 일측성 양성 종양으로 정확 한 문진, 이학적 검사 및 영상 소견 등을 종합하여 진단할 수 있었다. 외이도 골종은 수년간에 걸쳐 서서히 커지기 때문에 제거를 고려하게 되며, 조기에 시행한다면 비교적 간단한 수 술을 통해 쉽게 제거할 수 있고 재발은 흔하지 않았다.

\section{ORCID}

Hahn Jin Jung

https://orcid.org/0000-0002-6015-7048

See-Ok Shin

https://orcid.org/0000-0002-6778-9347

\section{REFERENCES}

1) Sheehy JL. Diffuse exostoses and osteoma of the external auditory canal: A report of 100 operations. Otolaryngol Head Neck Surg 1982;90(3 Pt 1):337-42.

2) Pulec JL, Deguine C. Osteoma of the external auditory canal. Ear Nose Throat J 1993;72(2):112.

3) Noordzij JP, Arriaga MA, Stone AB. Differentiating bony lesions of the external auditory canal. Ear Nose Throat J 1995;74(1):49-51.

4) Shenoy P, Paulose KO, Khalifa SA, Sharma R. Osteoma of the ear canal presenting with headache. J Laryngol Otol 1989;103(7):683-4.

5) Toma AB, Fisher EW. Osteoma of the external auditory meatus presenting as an aural polyp. J Laryngol Otol 1993;107(10):935-6.

6) Graham MD. Osteomas and exostoses of the external auditory canal. A clinical, histopathologic and scanning electron microscopic study. Ann Otol Rhinol Laryngol 1979;88(44 Pt 1):566-72.

7) DiBartolomeo JR, Paparella M, Meyerhoff WL. Cysts and tumors of the external ear. In: Paparella MM, Shumrick DA, Gluckmann JL, Meyerhoff WL, editors. Otolaryngology. 3rd ed., Vol. 2. Philadelphia: WB Saunders Company;1991. p.1243-58.

8) Valvassori GE, Mafee MF, Carter BL. Imaging of the Head and Neck. New York: Thieme Medical Publishers Inc;1995. p.110-31.

9) Denia A, Perez F, Canalis RR, Graham MD. Extracanalicular osteomas of the temporal bone. Arch Otolaryngol 1979;105(12):706-9.

10) Friedmann I, Arnold W. Cartilaginous and osteogenic neoplasms. In: Pathology of the EAR. Edinburgh: Churchill Livingstone;1993. p.307-11.

11) Kemink JL, Graham MD. Osteomas and exostoses of the external auditory canal-medical and surgical management. J Otolaryngol 1982;11(2):101-6.

12) Lee YS, Park YL, Lee IH. Osteoma of the external auditory canal. Korean J Otolaryngol-Head Neck Surg 1983;26(4):871-4.

13) Lee HK, Kang SH, Kang JW, Lee WS. A case of osteoma of the external auditory canal. Korean J Otorhinolaryngol-Head Neck Surg 1994;37(1):152-6.

14) Nam BH, Chang JW, Byun SN, Park CI. Osteoma of the external auditory canal. Korean J Otorhinolaryngol-Head Neck Surg 2000;43 (4):373-6.

15) Umeda Y, Nakajima M, Yoshioka H. Surfur's ear in Japan. Laryngoscope 1989;99(6 Pt 1):639-41.

16) Fenton JE, Turner J, Fagan PA. A histopathologic review of temporal bone exostoses and osteoma. Laryngoscope 1996;106(5 Pt 1):624-8. 